\title{
AiP1, a protein from the coelomic fluid of sea star Astropecten indicus promotes wound healing and fibrinogenolysis in vitro
}

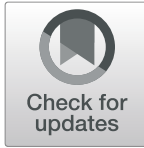

Mansi Baveja, Angshuman Sarkar, Sukanta Mondal, Jigni Pathan and Dibakar Chakrabarty * (D

\begin{abstract}
Background: Marine animals are suspected to hold keys to counter several life-threatening diseases. Despite its vast biodiversity, the marine ecosystem is relatively unexplored for its therapeutic potential. This study was particularly aimed at finding a potent molecule against thrombosis from the coelomic fluid of a sea star (SCF). SCF is a reservoir of immunocytes, coelomocytes, cytokines, and other substances responsible for the exceptional regenerative potential and other bioactivities. Death due to thrombosis has increased significantly in the recent years. Healing of wounds caused due to accidents or surgical procedures is also of great significance, particularly for diabetic patients. Therefore, search for good thrombolytic and wound healing agents is being pursued by many research groups globally.

Methods: SCF was fractionated using ion-exchange chromatography and size exclusion HPLC to yield a potent protein, AiP1. Proteolytic assays were performed using SDS-PAGE and zymography. Cell culture studies were performed as per standard protocols.
\end{abstract}

Results: Purified protein, AiP1, showed fibrinogenolytic, fibrinolytic, and anti-platelet activities in a dose-dependent manner. Proteolytic activities of AiP1 were inhibited post treatment with EDTA, indicating its metalloproteinase nature. It was also devoid of cytotoxic, hemolytic, and phospholipase activities. Scratch wounds created on surface of HEK293 and HaCaT cells showed faster wound closure rates post treatment with AiP1 compared to untreated cells. Peptide mass fingerprinting showed the presence of vWFA-like domain in the central $\beta$ sheet which may be responsible for its bioactivities. AiP1 was thus isolated and characterized for its thrombolytic and wound healing potential.

Conclusion: Coelomic fluid of sea stars contains many bioactive compounds. One such compound is the protein AiP1 containing a vWFA-like domain. This protein showed significant wound healing and thrombolytic activities in vitro.

Keywords: Astropecten indicus, Bioactive peptide, Marine natural product, Wound healing, Fibrinogenolysis, von Willebrand factor

\footnotetext{
* Correspondence: dibakarchakrabarty@goa.bits-pilani.ac.in; diba27@yahoo.com

Department of Biological Sciences, BITS Pilani K K Birla Goa campus, NH 17/B,

Zuarinagar, Goa 403726, India
} 


\section{Highlights}

1. Sea star coelomic fluid (SCF) aids in fibrinogenolysis and wound healing.

2. A protein, AiP1 of molecular weight $66 \mathrm{kDa}$ was purified from SCF.

3. AiP1 may contain von Willebrand factor superfamily A (vWFA)-like domain.

4. AiP1 promotes fibrinogenolysis and wound healing in vitro.

\section{Background}

The marine environment covers more than $70 \%$ of the earth's surface and marine organisms constitute more than $50 \%$ of the biodiversity (Montaser \& Luesch, 2011). Oceans, thus remain the largest resource of novel bioactive compounds and leads for drug development (Bordbar, Anwar, \& Saari, 2011; Datta, Nath Talapatra, \& Swarnakar, 2015; Hamed, Özogul, Özogul, \& Regenstein, 2015). Out of the many unexplored marine bioresources, one is the coelomic fluid of sea star Astropecten indicus. This species of sea stars is commonly found around the coast of South-East Asian countries and its coelomic fluid is a reservoir of bioactive compounds of diverse therapeutic as well as cosmetic potential (Kijjoa \& Sawangwong, 2004). Thrombosis and thromboembolic disorders are among the highest causes of mortality worldwide. Present day thrombolytic agents are associated with adverse side effects like unanticipated bleeding, hemorrhage, and lack of specific site of action (Engelmann \& Massberg, 2013; Key, Makris, \& Lillicrap, 2016; Lau, 2003). This makes the search for novel and potent thrombolytic drugs from natural sources imperative. Blood coagulation is a complex physiological process by which blood forms clots. Blood clots contain a meshwork of fibers running in different directions and capturing plasma, blood cells, and platelets. The fibrin fibers enwrap the accumulated and aggregated platelets, forming a hemostatic plug which adheres to the vascular opening and thus prevents further loss of blood. A series of factors (called blood coagulation factors) participate in the coagulation cascade in an orchestrated manner. In order to search for a novel thrombolytic agent, a protein was isolated which targets one or more of the blood coagulation factors. In this study, AiP1, a protein purified from the coelomic fluid of Astropecten indicus digested fibrinogen, the first blood coagulation factor.

Skin is the largest organ of the body and is constantly exposed to various stress conditions. In response to dermal injuries, the epidermis initiates a wound healing activity in response to skin damage (Choi, Yang, Kulkarni, Moh, \& Kim, 2015). Wound healing is a complex mechanism which comprises of the following steps: hemostasis, inflammation, proliferation, and remodeling. All these four steps must occur sequentially and within a proper time frame for the wound to heal successfully (Guo \& DiPietro, 2010). If any one of these phases is affected, impaired wound healing occurs, which pose risk-like inflammation, infection, necrosis, or ulcers (Han \& Ceilley, 2017).

Keeping in mind the aforementioned gaps in existing literature, this study focused on the isolation of thrombolytic and wound healing agent(s) from the coelomic fluid of the sea star Astropecten indicus. Protein extraction was performed using a combination of anion-exchange chromatography and size exclusion HPLC to yield AiP1. This protein was found to be thrombolytic with its fibrinogen and fibrin digesting activities. It also showed cell proliferative and wound healing activities in vitro. The role of AiP1 in cell migration was assessed by treating HEK293 cells with AiP1 and studying the change in expression of $\mathrm{E}$ and $\mathrm{N}$ cadherin. $\mathrm{E}$ and $\mathrm{N}$ cadherin are calcium-dependent trans-membrane adhesion proteins that form hemophilic interactions with similar molecules present on other cells, thus forming cellcell interactions. Increase in expression of $\mathrm{N}$ cadherin in HEK293 cultured cells post treatment with the protein AiP1 isolated from Astropecten indicus confirmed its role in cell migration (Maitre \& Heisenberg, 2013; Zuppinger, Eppenberger-Eberhardt, \& Eppenberger, 2000). The protein AiP1 was devoid of cytotoxic, hemolytic, phospholipase, and laminin digestion activities. Other biological activities present in AiP1 are currently being explored.

\section{Materials and Methods}

All reagents for biochemical assays were of analytical grade and purchased from Sigma Aldrich, USA. Protein molecular weight markers were purchased from GeneI, Bangalore, India. Reagents for platelet aggregation studies were purchased from Wheecon Instruments Pvt. Ltd., Chennai, India. Reagents for cell culture were purchased from Hi-Media and Sigma Aldrich, USA. Plastic wares were purchased from Tarsons, India, and Corning, USA.

\section{Preparation of sea star coelomic fluid (SCF)}

The detailed procedure about preparation of Sea star coelomic fluid (SCF) was described by the same authors previously (Baveja, Sarkar, \& Chakrabarty, 2018). Briefly, sea stars Astropecten indicus were collected from the coast of Goa, India, and $100 \mu \mathrm{l}$ or less coelomic fluid was extracted from the sea stars by syringe aspiration. The sea stars species was identified by the Zoological Survey of India. The extracted coelomic fluid from 2500 animals gave approximately $250 \mathrm{ml}$ of coelomic fluid. The extracted coelomic fluid from each sea star was pooled and centrifuged at $10000 \mathrm{rpm}$ for $15 \mathrm{~min}$. under cooling conditions, to remove cell debris and other contaminants from sea water. The supernatant was pooled and subjected to ultra-filtration using a $10 \mathrm{kDa}$ cut-off membrane. Filtrate and residue were collected separately 
and stored at $4{ }^{\circ} \mathrm{C}$. The retentate were dialysed against milliQ water for $2 \mathrm{~h}$ followed by dialysis against $50 \mathrm{mM}$ potassium phosphate buffer of $\mathrm{pH} 7.4$ (KPB) overnight with buffer changes after $3 \mathrm{~h}, 5 \mathrm{~h}$, and $10 \mathrm{~h}$. The dialysed fluid was concentrated using sucrose and stored in aliquots of $10 \mathrm{ml}$ in $-20{ }^{\circ} \mathrm{C}$ until further use.

\section{Estimation of protein concentration using Bradford's Assay}

Protein content in SCF and its fractionated proteins was estimated using Bradford protein assay (Bradford, 1976). The protein profile was studied by running the protein samples in a $12 \%$ SDS-PAGE followed by staining with Coomassie Brilliant Blue R-250 (CBB-R250) purchased from Thermo Fisher Scientific, India, or by silver staining.

\section{Assessment of protein purity}

Purity of all protein fractions and SCF was assessed by SDS-PAGE followed by visualization of bands using CBB $\mathrm{R}-250$ or silver staining technique.

\section{Effect on platelet aggregation}

SCF was studied for its effects on adenosine di-phosphate (ADP) and collagen-induced platelet aggregation using Chronolog whole blood platelet aggregometer (purchased from Wheecon Instruments Pvt. Ltd). Human blood (9 $\mathrm{ml}$ ) was freshly collected from "O" positive, healthy volunteers with prior and informed consent (via approval number IHEC-43/17-1 obtained from Institute Human Ethical Committee of Birla Institute of Technology and Science-Pilani), in $3.8 \%$ sodium citrate $(1 \mathrm{ml})$ under expert medical supervision. All studies were carried out using the whole blood platelet aggregometer. Blood was incubated with $0.85 \%$ saline (1:1 dilution) in a cuvette for $5 \mathrm{~min}$ at $37^{\circ} \mathrm{C}$. Platelet aggregation agonists ADP $(10 \mu \mathrm{M})$ or collagen $(2 \mu \mathrm{g} / \mathrm{ml})$ added to the above mixture served as positive controls. As a platelet agonist is added to the mixture, platelets aggregate as a monolayer on the electrical probes immersed in the cuvettes. Accumulation of platelets offers a resistance (or impedance) to the electrical circuit which is quantified in ohms. Change in impedance is expressed as a function of time. Protein fraction(s) incubated with the blood, saline, and agonist mixture served as test samples. Blood incubated with $0.85 \%$ saline served as negative control. Positive control showed maximum resistance. Negative controls were devoid of any agonists for aggregation and hence offered negligible resistance (Chanda, Sarkar, Sistla, \& Chakrabarty, 2013).

\section{Fibrinogenolytic activity}

Human fibrinogen was suspended in potassium phosphate buffer (KPB), $\mathrm{pH} 7.4$, and incubated with varying doses of SCF or test protein for $5 \mathrm{~h}$ at $37^{\circ} \mathrm{C}$. Fibrinogenolytic activity was assessed by running the pre-incubated samples on a $12 \%$ SDS-PAGE. Fibrinogenolytic activity was confirmed by disappearance of one or more chains of fibrinogen observed by Coomassie staining of the gel. Fibrinogen $(30 \mu \mathrm{g})$ yielded three protein bands viz $\mathrm{A} \alpha, \mathrm{B} \beta$, and $\gamma$ when run on a $12 \%$ SDS-PAGE. SCF upon incubation with fibrinogen led to the sequential degradation of $\mathrm{A} \alpha, \mathrm{B} \beta$, and $\gamma$ bands in a dose and time-dependent manner (Chanda, Sarkar, \& Chakrabarty, 2016).

\section{Proteolytic activity using substrate zymography}

Zymogram protease assay was performed to estimate different kinds of protease activities (fibrinolytic, fibrinogenolytic, and caseinolytic) of the protein components of SCF and AiP1. The protein substrate $(10 \mathrm{mg})$ was copolymerized with acrylamide during preparation of the polyacrylamide gel, followed by electrophoresis of SCF and proteins fractionated from SCF on the same gel using native page running conditions. The gel was washed with Triton-X (two times) to remove the SDS and followed by incubation in Tris- $\mathrm{CaCl}_{2}$ buffer, $\mathrm{pH} 7.4$, at 37 ${ }^{\circ} \mathrm{C}$ for pre-determined time periods. Protease activity of samples was observed by staining the gel with $1.25 \%$ CBB. The entire gel was stained due to presence of protein substrate embedded in it. Protease activity of the active proteins present in the loaded samples was observed as regions devoid of stain on the gel due to digestion of protease substrate by them (Leber \& Balkwill, 1997; Masure, Proost, Van Damme, \& Opdenakker, 1991).

\section{Molecular weight determination}

Molecular weight of the purified protein after HPLC was determined by a standard curve constructed from the values obtained from retention time and proteins of known molecular weights provided as a standard protein mixture from Phenomemex, India. The standard protein mixture comprised of bovine thyroglobulin, IgA, IgG, ovalbumin, myoglobin, and uridine.

\section{lon-exchange chromatography}

SCF $(1 \mathrm{mg} / \mathrm{ml})$ was loaded on a $5 \mathrm{ml}$ column of diethyl amino ethyl (DEAE) Sephadex A-25 resin. Mobile phase used was $50 \mathrm{mM}$ potassium phosphate buffer, $\mathrm{pH}$ 7.4. Adsorbed proteins were eluted with a linear gradient of sodium chloride ( 0 to $0.5 \mathrm{M}$ ), and $1-\mathrm{ml}$ fractions were collected.

\section{Size exclusion chromatography using HPLC}

The protein peaks showing specific biological activities obtained by ion-exchange chromatography were subjected to size exclusion chromatography using a BioSep SEC s2000 column (Phenomenex) on HPLC system (UFLC LC 20 AD Prominence) purchased from Shimadzu. The mobile phase was $50 \mathrm{mM}$ potassium phosphate buffer, $\mathrm{pH}$ 
7.4. One sharp protein peak was eluted which was studied further.

MALDI TOF MS/MS (mass spectrometeric) analysis of AiP1 The protein isolated from SCF post HPLC was outsourced to the Protein Facility Laboratory of Iowa State University, IA, USA to assess its partial sequence. The protein was digested using trypsin followed by MS/MS analysis. The peptide fragments of AiP1 were scanned using BLASTP (version 2.8.0) against the NCBI nr data bases to find homology with non-redundant proteins (Johnson et al., 2008).

\section{In vitro culture of cells}

Cell stocks of HEK293 and human keratinocytes (HaCaT) were revived in $25-\mathrm{cm}^{2}$ culture flasks in DMEM supplemented with $10 \%$ FBS and $1 \mathrm{X}$ antibiotic and anti-mycotic solution at $37{ }^{\circ} \mathrm{C}$ in a humidified $\mathrm{CO}_{2}$ incubator. Cells were passaged every third or fourth day upon reaching confluence. Cells were seeded for cytotoxicity studies and wound healing studies at a seeding density of 20,000 cells/ml.

\section{Cell counting by Trypan Blue dye exclusion assay}

This assay relies on the ability of the dye to enter dead cells or cells with ruptured membranes. It is a direct indicator of cell death. Upon reaching confluence, cells were detached using trypsin and counted using a hemocytometer. Viable cells were counted used for further experimentation (Strober, W. 2015).

Estimation of cytotoxicity by MTT (3-(4, 5-dimethylthiazolyl2)-2, 5-diphenyltetrazolium bromide) assay

The effect of SCF and AiP1 on cell viability was assessed by the MTT assay, which is an indicator of the metabolic activity of cells. HEK293 and $\mathrm{HaCaT}$ cells were assessed separately for the effect of SCF and AiP1 on their viability. Cells were seeded into 96-well plates at a seeding density of 20,000 cells/ml. Upon reaching confluence, the used media was decanted and fresh media containing varying doses of $\mathrm{AiP} 1$ were added to different wells of the 96-well plate and incubated for the desired time intervals in $37{ }^{\circ} \mathrm{C}$ humidified incubator. Once the incubation period was completed, the complete media was removed and $100 \mu \mathrm{l}$ of MTT $(1 \mathrm{mg} / \mathrm{ml})$ was added to the cells and covered with a sterile aluminum foil and incubated at $37{ }^{\circ} \mathrm{C}$ for $3-4 \mathrm{~h}$ until formazan crystals were formed. The formazan crystals were dissolved by adding DMSO, and absorbance was measured at $550 \mathrm{~nm}$ using a 96-well plate reader. Cytotoxicity was estimated at \% loss in cell viability taking untreated cells as control (Berridge et al., 2005; Pathan et al., 2017 and Patravale et al., 2012).

\section{In vitro scratch assay for estimation of wound healing} activity HEK293 and HaCaT cells were cultured in vitro in T-25 flasks as described in the "In vitro culture of cells" section. Cells were seeded at $70 \%$ confluence in 6-well plates at a seeding density of 30,000 cells/ml and were left overnight in sterile humidified conditions. Upon $60 \%$ cell confluence, the spent media was discarded from the wells followed by washing with phosphate buffer saline (PBS) to remove unattached cells. A longitudinal scratch was made in each well using a sterile $200-\mu \mathrm{l}$ pipette tip. The cells were again washed with PBS, and $2 \mathrm{ml}$ of DMEM supplemented with $10 \%$ FBS and $0.01 \%$ antibiotic solution was added to each well of the culture plate. AiP1 at different doses was added to the well such that the final volume in each well was $2 \mathrm{ml}$. Images were taken for each well at time intervals of $24 \mathrm{~h}$ to observe effect of SCF on the wounds. Area of the wound was calculated using Image J software, and wound healing activity of AiP1 was expressed as the \% wound healed at the given time period using initial wound area (0th hour) as reference (Liang et al., 2007; Baveja et al., 2018).

\section{Reverse transcription polymerase chain reaction (RT-PCR) for cDNA synthesis}

The effect of AiP1 on RNA expression was assessed by electrophoresing the PCR products on $1.2 \%$ agarose gel. Total RNA was isolated from AiP1-treated HEK293 cells (after 24 and $48 \mathrm{~h}$ ) using TRIzol ${ }^{\circledR}$ LS Reagent (Invitrogen, USA) as per the manufacturer's protocol. The RNA was reverse transcribed, and $c \mathrm{DNA}$ was synthesized using the $c$ DNA synthesis kit for RT-PCR (Tetro $c$ DNA synthesis kit from Bioline, USA) as per instructions provided in the kit. Amplification of $c$ DNA was performed using PCR using specific primers. The primers utilized for RT-PCR were as follows: GAPDH (forward: 5 '-AAG CCT GCC GGT GAC TAA C-3', reverse: 5'-GCG CCC AAT ACG ACC AAA TC-3'); E-cadherin (forward: 5' GAT CCA TTT CTT GGT CTA CGC-3', reverse: 5' TGG TGA TTA TTA CGA CGT TAG CC-3'); $N$-cadherin (forward: 5'-CAA CTT GCC AGA AAA CTC CAG G-3', reverse: 5' -ATG AAA CCG GGC TAT CTG CTC-3'); and glyceraldehyde-3-phosphate dehydrogenase $(G A P D H)$ (forward: $5^{\prime}$-AGA ACA TCA TCC CTG CCT CTA C-3', reverse: 5' -CTG TTG AAG TCA GAG GAG ACC A-3'). All PCR conditions were normalized to the GAPDH expression. The $c$ DNA synthesized was stored in aliquots in $-20{ }^{\circ} \mathrm{C}$. The effect of AiP1 on RNA expression was assessed by electrophoresing the PCR products on $1.2 \%$ agarose gel. PCR conditions for expression studies were normalized using GAPDH. PCR conditions were initial denaturation $\left(2 \mathrm{~min}\right.$ at $\left.97^{\circ} \mathrm{C}\right)$, denaturation $\left(35\right.$ cycles for $1 \mathrm{~min}$ at $94{ }^{\circ} \mathrm{C}$ ), annealing $(1$ $\min 30 \mathrm{~s}$ at $57{ }^{\circ} \mathrm{C}$ ) for $\mathrm{GAPDH}$, extension $(1 \mathrm{~min}$ at 70 
${ }^{\circ} \mathrm{C}$ ), and final extension $\left(5 \mathrm{~min}\right.$ at $\left.70{ }^{\circ} \mathrm{C}\right)$. The relative expression of $\mathrm{E}$ cadherin and $\mathrm{N}$ cadherin in untreated as well as in cells treated with AiP1 was measured via densitometry analysis (Pathan et al., 2017).

\section{Results}

Fractionation of SCF using DEAE Sephadex A-25 column Fractionation of SCF was performed using a $5-\mathrm{ml}$ column of DEAE Sephadex A-25 using mobile phase of $50 \mathrm{mM}$ $\mathrm{KPB} \mathrm{pH}$ 7.4. Proteins were eluted using a linear gradient of $\mathrm{NaCl}(0$ to $0.5 \mathrm{M})$. One major protein peak (P-A) and two minor peaks were eluted as seen in Fig. 1A. Protein fractions comprising P-A were assessed by running on $12 \%$ SDS-PAGE. Protein bands were visualized using silver staining of the gel (Fig. 1B).

\section{Fibrinogenolytic activity of fractions of P-A}

Protein fractions comprising P-A were pooled, concentrated, and studied for their effect on fibrinogen. Fibrinogen contains three chains, $A \alpha, B \beta$, and $\gamma$. Digestion of any one of these chains renders a compound fibrinogenolytically active. Fibrinogenolytic activity was assessed by incubating the individual fractions with fibrinogen as substrate at $37^{\circ} \mathrm{C}$ for $5 \mathrm{~h}$. Fibrinogen incubated with saline served as the negative control (Fig. 2).

\section{Size exclusion HPLC of P-A}

The protein fractions comprising $\mathrm{P}-\mathrm{A}$ were pooled, dialysed, concentrated, and fractionated using HPLC on a size exclusion column. One major protein peak and several smaller peaks were eluted as seen in Fig. 3. The protein fraction eluted at the 23rd min was assessed for its purity by SDS-PAGE. A single protein band was obtained having molecular weight of $66 \mathrm{kDa}$. This protein would be referred to as AiP1.

\section{Fibrinogenolytic activity of AiP1}

Fibrinogenolytic activity of AiP1 was estimated in a dose- and time-dependent manner as shown in Fig. 4. Fibrinogenolysis by AiP1 was seen as digestion of one or more chains of fibrinogen. As seen from the figure, $A \alpha$ chain of fibrinogen was digested above AiP1 dose of $8 \mu \mathrm{g}$, followed by digestion of both $\mathrm{A} \alpha$ and $\mathrm{B} \beta$ chains at doses higher than $8 \mu \mathrm{g}$ of AiP1. Ten micrograms of AiP1 dose was standardized for its fibrinogenolytic potency. Time-dependent studies revealed fibrinogen digestion by AiP1 $(10 \mu \mathrm{g})$ upon incubation at $37{ }^{\circ} \mathrm{C}$ for more than $3 \mathrm{~h}$. Fibrinogen incubated with saline served as the negative control.

\section{Inhibition of fibrinogenolytic activity of AiP1}

The nature of protease activity was assayed by incubating AiP1 with EDTA (metallo-protease inhibitor) or PMSF (serine protease inhibitor) for $1 \mathrm{~h}$ followed by assessing its fibrinogenolytic activity as shown in Fig. 5. It was observed that treatment of AiP1 with EDTA for $30 \mathrm{~min}$ reduced its fibrinogenolytic activity. Furthermore, incubation with EDTA for $1 \mathrm{~h}$ completely inhibited the fibrinogenolytic activity of AiP1. This indicated the metalloproteinase nature of AiP1.

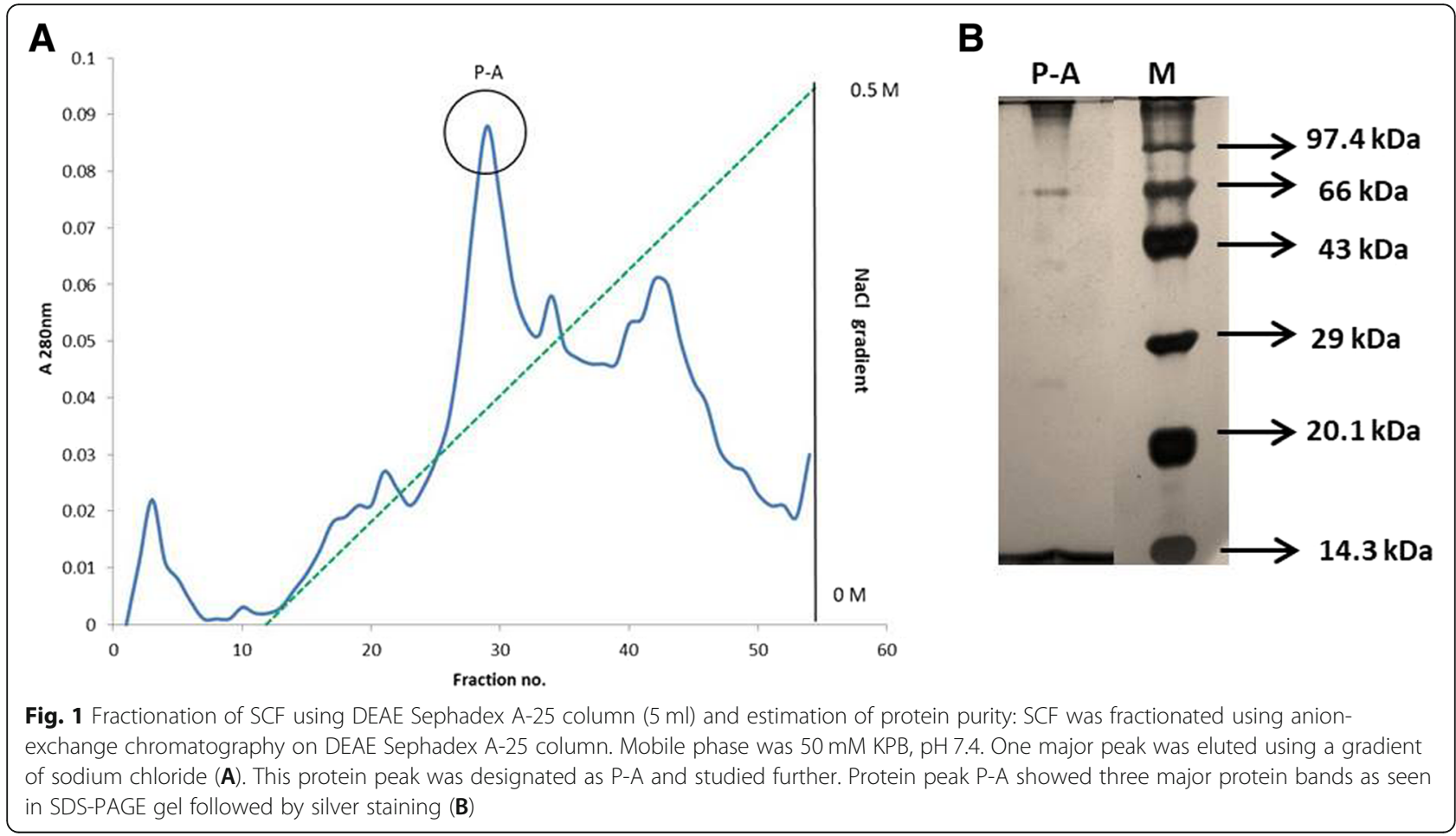




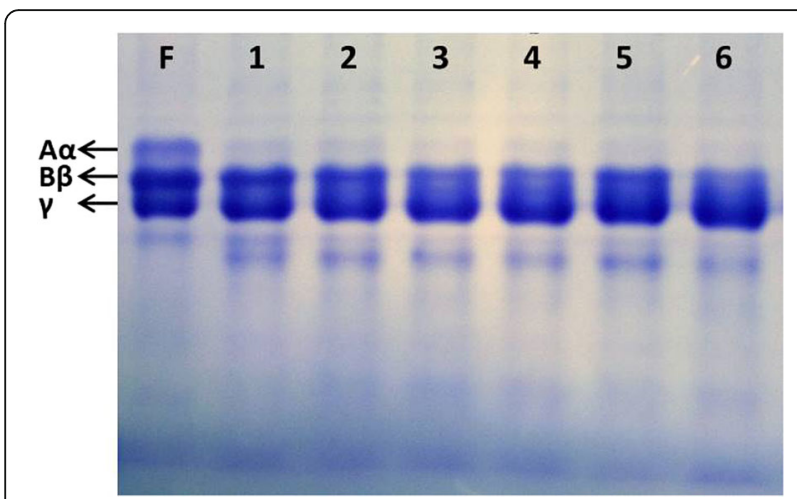

Fig. 2 Fibrinogenolysis by protein fractions of peak P-A: $F$ is fibrinogen which served as negative control; lanes 1 to 6 are protein fractions comprising peak P-A incubated with fibrinogen at $37{ }^{\circ} \mathrm{C}$ for $5 \mathrm{~h}$. All fractions of protein peak P-A lysed fibrinogen as seen as disappearance of the Aa chain in lanes 1 to 6

\section{Thermal stability of AiP1}

The effect of temperature on fibrinogenolytic activity of AiP1 was assayed by exposing AiP1 to various temperatures for 1 $\mathrm{h}$ followed by assessing the fibrinogen digesting ability of the samples post heat exposure. The protein AiP1 was found to withstand temperature of up to $70^{\circ} \mathrm{C}$, beyond which its fibrinogenolytic activity was inhibited as seen in Fig. 6.

\section{Fibrinolytic activity of AiP1}

Fibrinolytic activity of AiP1 was estimated using the zymogram assay. Fibrin was co-polymerized with the polyacrylamide gel, followed by electrophoresis of SCF and AiP1. The gel was incubated for $8 \mathrm{~h}$ in the incubation buffer at $37^{\circ} \mathrm{C}$. Fibrinolytic proteins showed clear digestion of the substrate as seen in Fig. 7.

\section{Effect of AiP1 on platelet aggregation}

The effect of AiP1 on blood platelets was assessed by a Chronolog Whole Blood Platelet Aggregometer using ADP and collagen as agonists. An increase in aggregation of ADP-activated platelets was observed post treatment with $2 \mu \mathrm{g}$ of AiP1 followed by a sequential inhibition of platelet aggregation at higher doses of AiP1 (Fig. 8A). For collagen-induced platelet aggregation, AiP1 showed a dose-dependent inhibition of platelet aggregation as seen in Fig. 8B.

Loss of platelet inhibiting activity of AiP1 was observed upon its treatment with EDTA as expected of its metalloproteinase nature.

\section{Peptide mass fingerprinting of AiP1}

The analyzed peptide fragments of AiP1 and their similarity search results (as described in the "MALDI TOF MS/MS (mass spectrometeric) analysis of AiP1" section) are summarized in Additional file 1: Table S1. Only in one of the peptide of AiP1, which had the amino acid sequence "RIMLFMGGPPTQGPGMVVGEELKT," the matched region was identical to a functional domain, the von Willebrand factor A (vWFA)-like domain superfamily (InterPro id IPR036465) from the organism

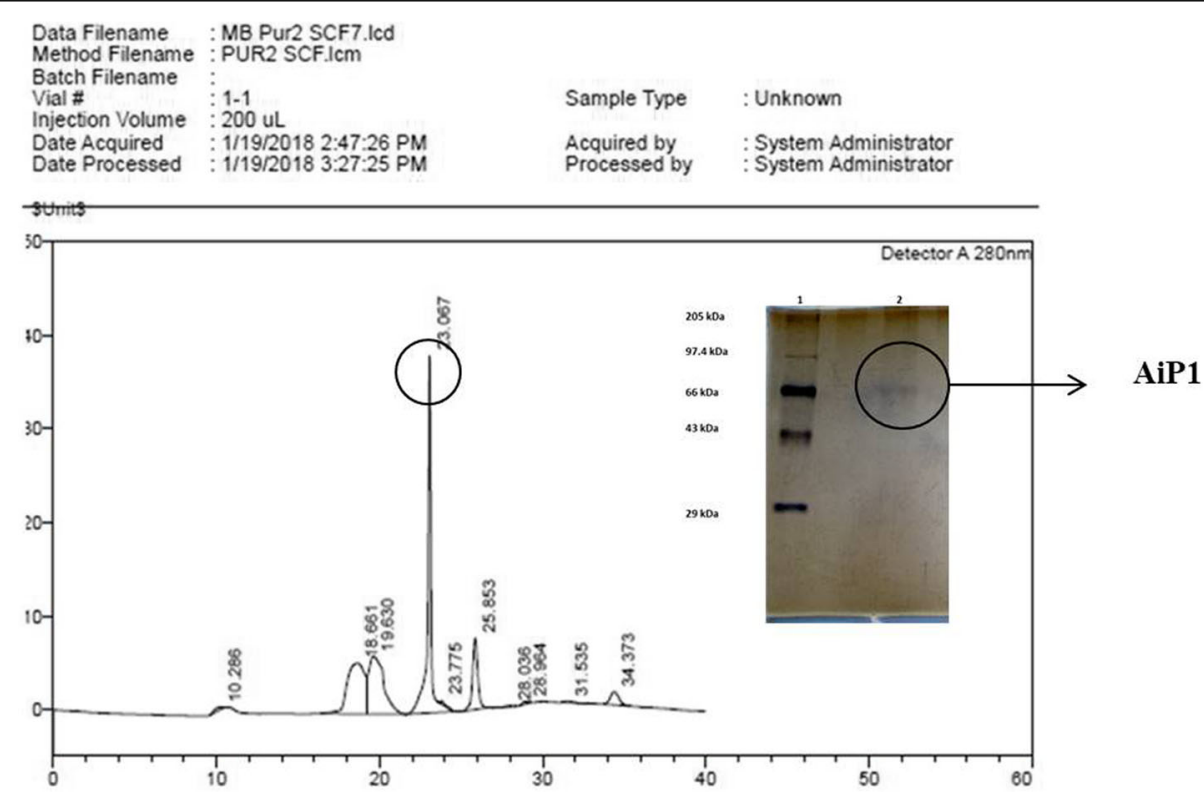

Fig. 3 Size exclusion HPLC of P-A: protein peak P-A was fractionated using HPLC on a size exclusion column. Flow rate $=0.5 \mathrm{ml} / \mathrm{min}$; $\mathrm{mobile}$ phase $=50 \mathrm{mM} \mathrm{KPB}, \mathrm{pH} 7.4$. One sharp protein peak was eluted at retention time of $23 \mathrm{~min}$. This peak was studied in detail in further sections. Inset is the protein purity and molecular weight estimation of AiP1. Lane 1 is high range protein molecular weight marker; lane 2 is AiP1. Molecular weight of AiP1 was estimated to be $66 \mathrm{kDa}$ 

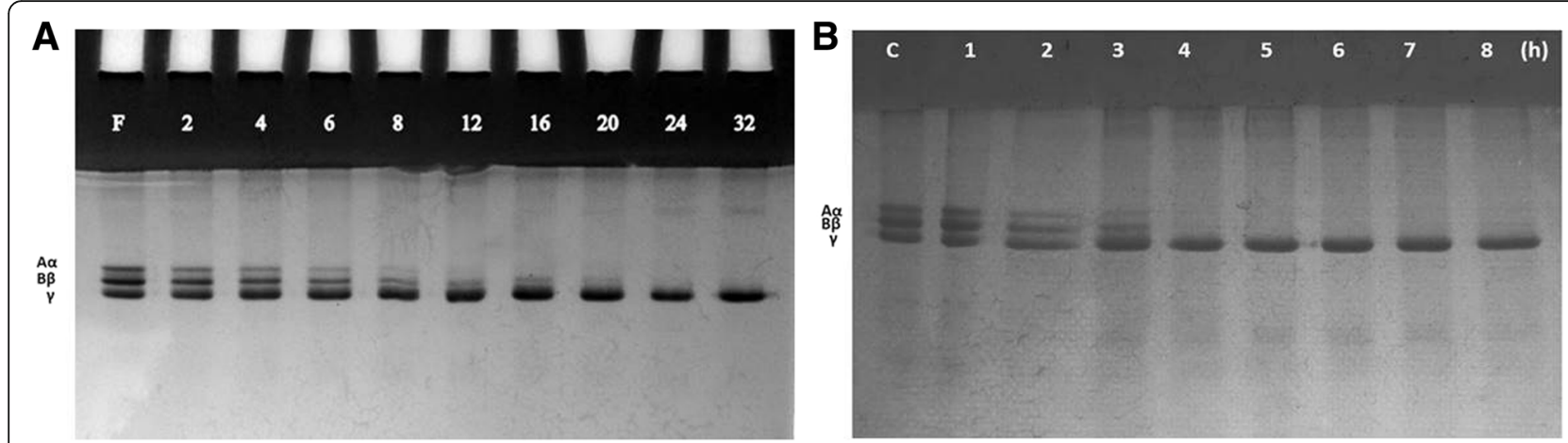

Fig. 4 Dose- and time-dependent fibrinogenolysis by AiP1: A Lane F is fibrinogen incubated with $0.85 \%$ saline (negative control); other lanes represent the dose of AiP1 (in $\mu \mathrm{g}$ ) incubated with fibrinogen. B Lane C is fibrinogen incubated with $0.85 \%$ saline (negative control); other lanes represent the time period of AiP1 $(10 \mu \mathrm{g})$ incubated with fibrinogen at $37^{\circ} \mathrm{C}$

Strongylocentrotus purpuratus. This peptide would be referred to as "peptide1" in subsequent sections. This peptide (peptide1) search was extended to another recently sequenced sea star, the crown of thorns or Acanthaster planci (Hall et al., 2017). The Fig. 9A shows "peptide1" aligned with homologous domains present in Strongylocentrotus purpuratus and Acanthaster planci. These three organisms belong to the same phylum Echinodermata. The similarity of "peptide1" from Astropecten indicus with that from other echinoderms such as purple sea urchin (Strongylocentrotus purpuratus) and crown of thorns starfish (Acanthaster planci) indicates that "peptide1" may have functional significance in echinoderms in their various biological processes.

The vWFA-like domain from Strongylocentrotus purpuratus was modeled using homology modeling to understand the potential role of "peptide1" matched region. The "peptide1" was observed to be an integral part of the central $\beta$ sheet of $\nu W F A$-like domain, and some part of it was overlapped with the predicted PPI residues, and thus, it may be structurally and functionally significant for echinoderms (Fig. 9B, C).

These results suggest that AiP1 may contain vWFAlike domain. Proteins that incorporate vWFA-like

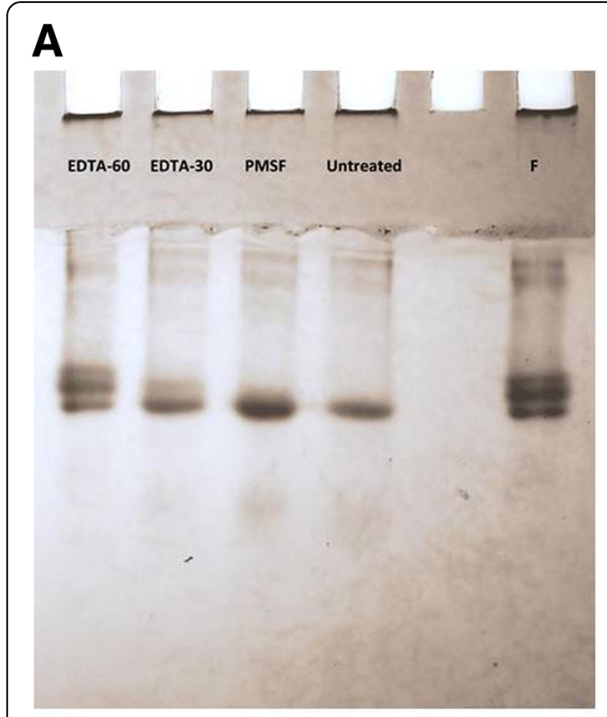

B

Fig. 5 Inhibition of fibrinogenolytic activity of AiP1 by EDTA: A Metalloproteinase nature of AiP1 was confirmed by estimating fibrinogenolytic activity of AiP1 post treatment with different inhibitors followed by incubating with fibrinogen to assess presence or loss of fibrinogenolytic activity post treatment. Lane 1: AiP1 treated with EDTA for 60 min; lane 2: AiP1 treated with EDTA for 30 min; lane 3: AiP1 treated with PMSF for 60 min; lane 4: untreated AiP1; lane 5: fibrinogen control. B Intensity of fibrinogen bands plotted against the AiP1 treated with various protease inhibitors. Digestion of Aa band of fibrinogen was maximum in untreated AiP1, AiP1 treated with PMSF, and AiP1 treated with EDTA for 30 min. Digestion of $\mathrm{B} \beta$ chain of fibrinogen was at maximum in untreated AiP1 followed by AiP1 treated with PMSF. ${ }^{*} p<0.05 ;{ }^{* *} p<0.01$ 


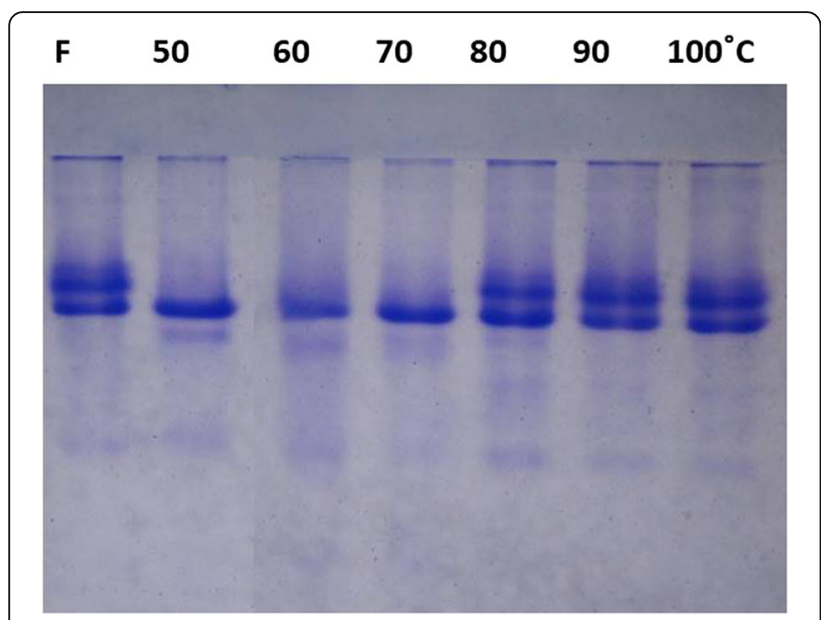

Fig. 6 Effect of temperature on fibrinogenolytic activity of AiP1: lane F is fibrinogen which served as negative control; other lanes represent the temperature (in ${ }^{\circ} \mathrm{C}$ ) at which AiP1 was exposed for $1 \mathrm{~h}$ before incubating with fibrinogen substrate. Fibrinogenolytic activity of AiP1 was retained till a temperature treatment of $70^{\circ} \mathrm{C}$ beyond which the activity was lost

domain are known to participate in numerous biological events (like cell adhesion, migration, homing, pattern formation, and signal transduction), involving interaction with a large array of ligands (Colombatti, Bonaldo, \& Doliana, 1993). This led us to study the effect of AiP1 on cell viability and migration in further sections.

\section{Effect of AiP1 on cell viability}

The effect of AiP1 on viability of HEK293 and $\mathrm{HaCaT}$ cells were assessed using the MTT assay. No loss in cell viability was observed in cells post treatment with AiP1

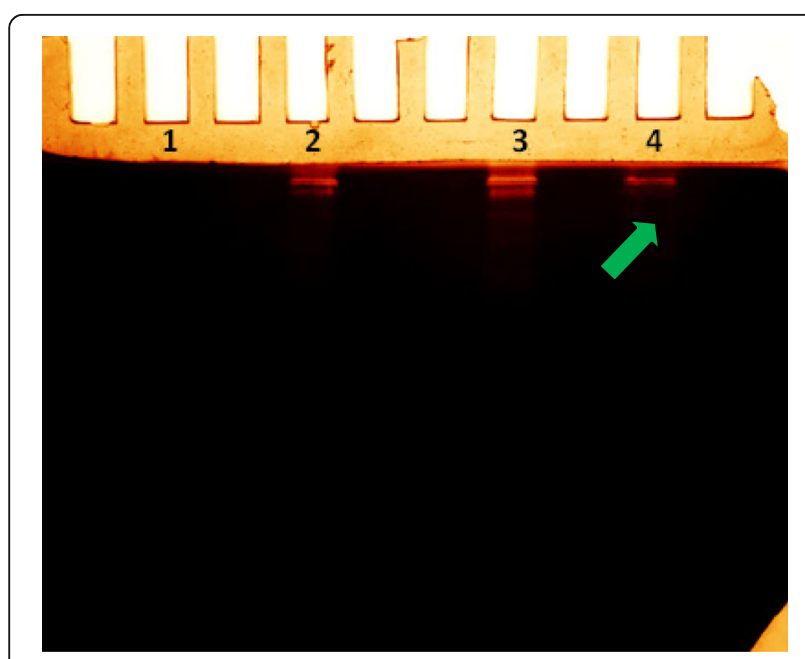

Fig. 7 Fibrinolytic activity of AiP1: Lane 1 is AiP1 treated with EDTA; lane 2 is SCF $(2.5 \mu \mathrm{g})$; lane 3 is SCF $(5 \mu \mathrm{g})$; lane 4 is AiP1 $(2.5 \mu \mathrm{g})$. Arrow indicates zone of fibrin digestion by AiP1AiP1 showed digestion of fibrin as observed by zones of substrate digestion in the zymogram for $24 \mathrm{~h}, 48 \mathrm{~h}$, and $72 \mathrm{~h}$. However, AiP1-treated cells showed an increase in viability as compared to those in untreated cells which served as control (Fig. 10).

\section{Wound healing activity of AiP1 on HEK293 and HaCaT cells} Wound healing activity of AiP1 was assessed using the monolayer scratch assay. Wounded cells treated with AiP1 showed faster wound closure rates compared to untreated cells which served as control. HEK293 cells showed wound closure in about $60 \mathrm{~h}$ whereas $\mathrm{HaCaT}$ cells showed complete wound closure within $48 \mathrm{~h}$ of incubation with AiP1, as seen in Fig. 11A, B.

\section{RT-PCR and CDNA synthesis-E and N cadherin expression}

Effect of AiP1 on expression of $\mathrm{E}$ and $\mathrm{N}$ cadherin was done by RT-PCR and $c$ DNA synthesis after various time intervals at $24 \mathrm{~h}$ and $48 \mathrm{~h}$. In the present study, the change in expression of E-cadherin post treatment with AiP1 could not be assessed due to low expression levels of E-cadherin in HEK293 cells, whereas a dose- and a time-dependent increase in $\mathrm{N}$ cadherin expression was observed in HEK293cells (Fig. 12A, B). This indicated that AiP1 promoted cell migration in vitro (Fig. 12).

\section{Discussion}

Echinoderms, especially sea stars, have been used as model organisms for regenerative studies due to their amazing regenerative potential (Dai, Prithiviraj, Gan, Zhang, \& Yan, 2016). The bio-molecules responsible for this property are predominantly the coelomocytes which are the immune cells present in the coelomic fluid (da Silva Laires, 2012). Despite their immense regenerative potential, little is known about the wound healing agents from sea stars, especially from the Astropecten genus. In this study, we explored the potential of AiP1, the first protein purified from Astropecten indicus for its thrombolytic and wound healing potential.

The fibrinogenolytic and wound healing potential of SCF from Astropecten indicus was previously reported in 2018 by the same authors (Baveja et al., 2018). SCF comprised of various proteins and polypeptides responsible for its bioactivities. In the present study, one of the many bioactive proteins from SCF was isolated and partially characterized. This protein, designated as AiP1, was fibrinogenolytically active at a concentration of $10 \mu \mathrm{g} / \mathrm{ml}$ as seen in the dose-dependent studies in Fig. 4. The proteolytic activity of AiP1 was persistent up to a temperature of $70{ }^{\circ} \mathrm{C}$ (Fig. 6). AiP1 promoted ADPinduced platelet aggregation at a dose of $2 \mu \mathrm{g} / \mathrm{ml}$. At higher doses, inhibition of aggregation was observed for ADP or collagen-induced platelets (Fig. 8). AiP1 was found to be a metalloproteinase, since it lost its activities in presence of EDTA (Fig. 5). 

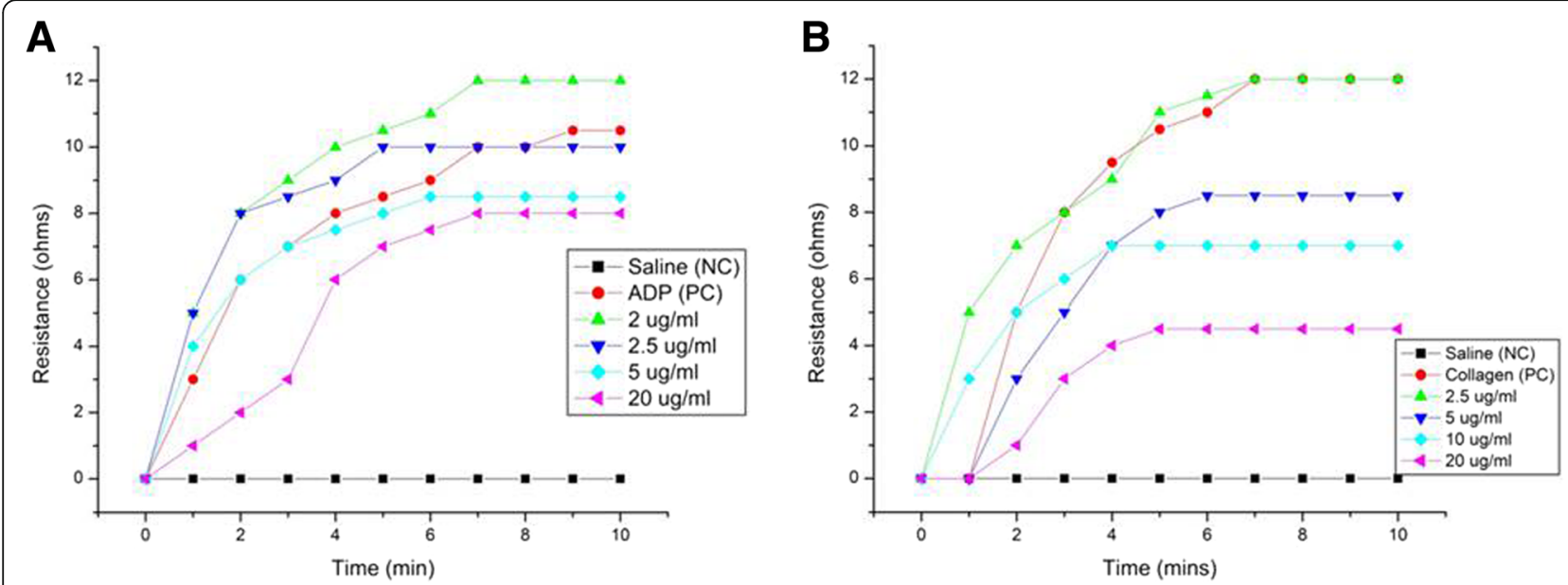

Fig. 8 Effect of AiP1 on ADP and collagen-induced platelet aggregation. A An increase in platelet aggregation was observed in platelets treated with $2 \mu \mathrm{g}$ of AiP1. At higher doses, a dose-dependent inhibition of platelet aggregation was observed; B A dose-dependent inhibition of collagen-induced platelet aggregation was observed upon treatment with AiP1

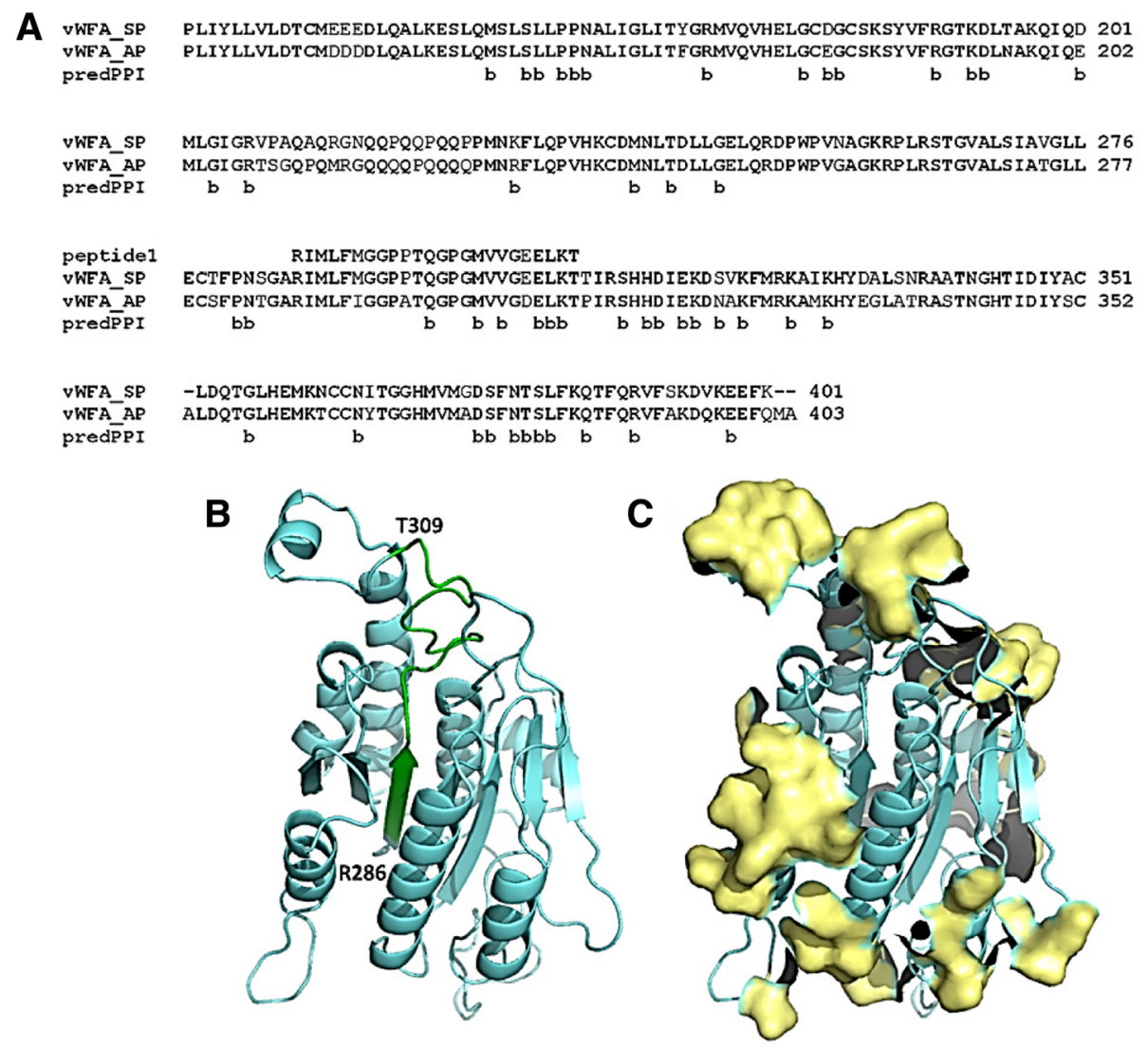

Fig. 9 VWFA-like domain from the organism Strongylocentrotus purpuratus and its putative functional sites. A Multiple sequence alignment of "peptide1" and VWFA-like domain from the organisms Strongylocentrotus purpuratus (VWFA_SP; NCBI RefSeq accession numbers XP_780042.1) and Acanthaster planci (VWFA_AP; NCBI RefSeq accession numbers XP_022096018.1). The alignment was generated using CLUSTAL Omega version 1.2.4 (/www.ebi.ac.uk/Tools/msa/clustalo/). Predicted solvent accessible protein-protein interacting residues (predPPI) are highlighted ("b"). Solvent accessibility and PPI residues were predicted using NetSurfP (version 1.1, http://www.cbs.dtu.dk/services/NetSurfP/) and LORIS (Dhole, Singh, Pai, \& Mondal, 2014), respectively. B Ribbon representation of the modeled VWFA_SP (5kyn_A as template with sequence identity $77.5 \%$ ) generated using SwissModel (Bienert et al., 2017). Highlighted position (green, R286 to T309) on this model is identical with "peptide1." C Predicted solvent accessible PPIs (predPPI) mapped on the modeled vWFA_SP. Figure $\mathbf{B}$ and $\mathbf{C}$ were generated using PyMol (version 2.2,https://pymol.org/) 


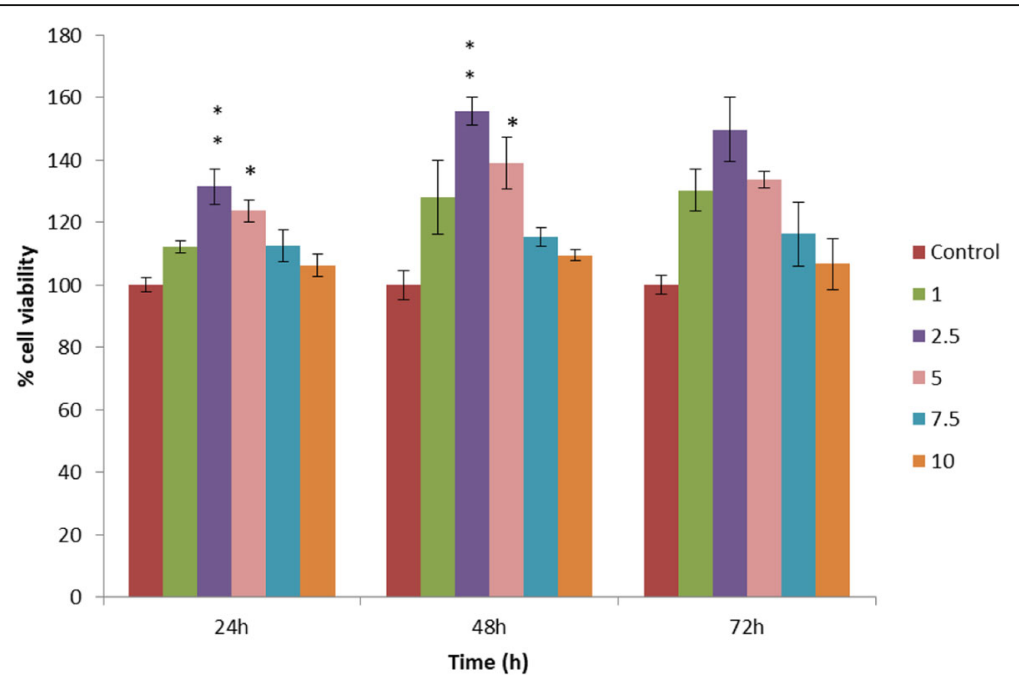

Fig. 10 Effect of AiP1 on viability of HEK293 cells in vitro: An increase in cell viability was observed post treatment with AiP1 compared to untreated cells (control). Doses up to $5 \mu \mathrm{g} / \mathrm{ml}$ AiP1 showed maximum increase in cell viability

The cell proliferative and wound healing activity of AiP1 was observed in vitro in human keratinocytes (HaCaT cells) and human embryonic kidney epithelial (HEK293) cells as seen as an increase in cell viability and cell migration in Figs. 10 and 11. Cadherins are calcium-dependent cell adhesion molecules that play an important role in cell-cell adhesion by forming adherent junctions. $\mathrm{N}$ Cadherin is important for cell migration by forming $\mathrm{N}$-cadherin-actin linkage. Cadherin switching, i.e., downregulation of E-cadherin and upregulation of $\mathrm{N}$ cadherin, plays a pivotal role in epithelial to mesenchymal transition (EMT) (Priya \& Yap, 2015). The change in expression of E-cadherin post treatment with AiP1 could not be assessed due to low expression levels of E-cadherin in HEK293 cells (Inada, Izawa, Kobayashi, \& Ozawa, 2016). An increase in N-cadherin expression in HEK293 cells post treatment with AiP1 (Fig. 10) further confirmed its role in cell migration and in wound healing.

AiP1 was found to contain a vWFA-like domain as seen in the "Peptide mass fingerprinting of AiP1" section. The von Willebrand factor is a plasma glycoprotein which aids in hemostasis and thrombosis by binding to blood coagulation factor VIII (FVIII) and tethers platelets to injured blood vessel wall (Butera et al., 2018; Peyvandi, Garagiola, \& Luciano, 2011). It is an indispensable adhesive substrate in platelet-platelet aggregation via the A1 domain binding to the GPIba (Hassan, Saxena, \& Ahmad, 2012; Matsushita \& Sadler, 1995; Ruggeri, 1997). The vWF

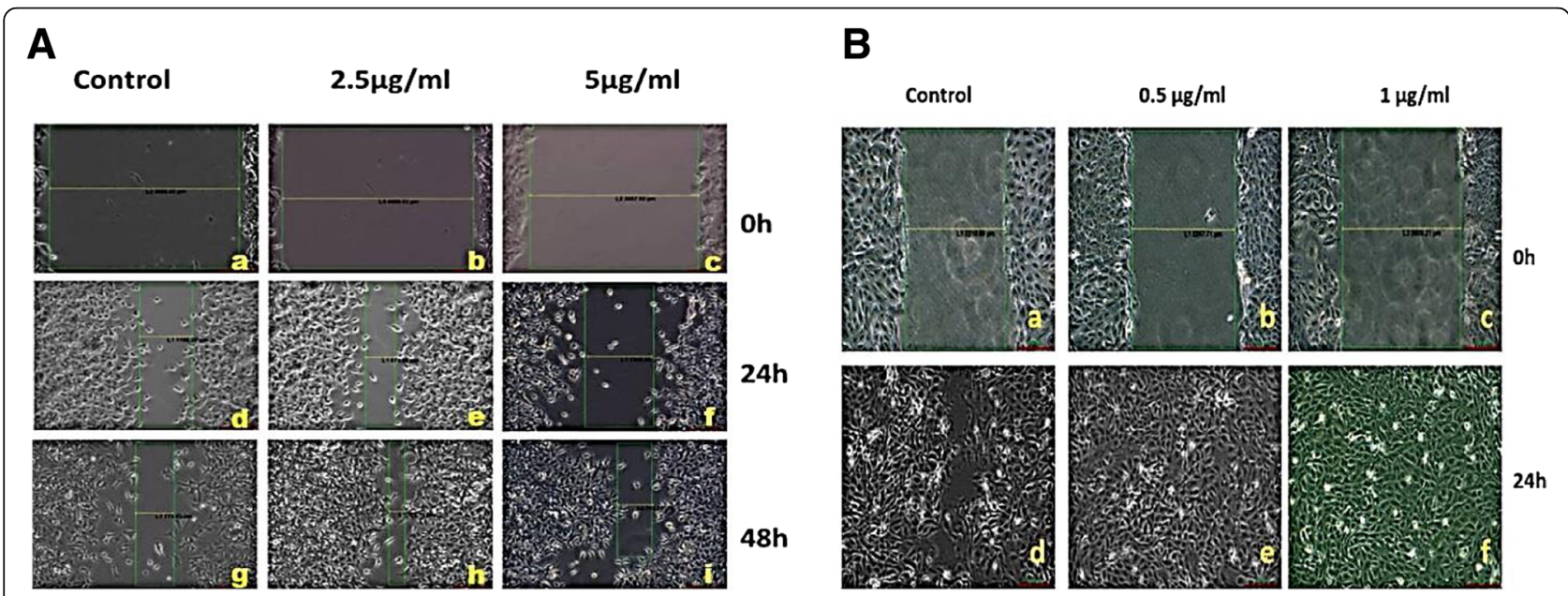

Fig. 11 Wound healing activity of AiP1 on HEK293 and HaCaT cells: A Wound healing was accelerated in AiP1-treated HEK293 cells compared to untreated cells which served as the control. Wound healing was observed at concentrations 2.5 and $5 \mu \mathrm{g} / \mathrm{ml}$ of AiP1 (as seen in sections e, f, h, and $\mathrm{i}$ of A). B Wound healing accelerated in HaCaT cells treated with AiP1 (sections b, c, e, and f of B) compared to untreated cells (sections a and $d$ of $\mathbf{B}$ ) which served as control 


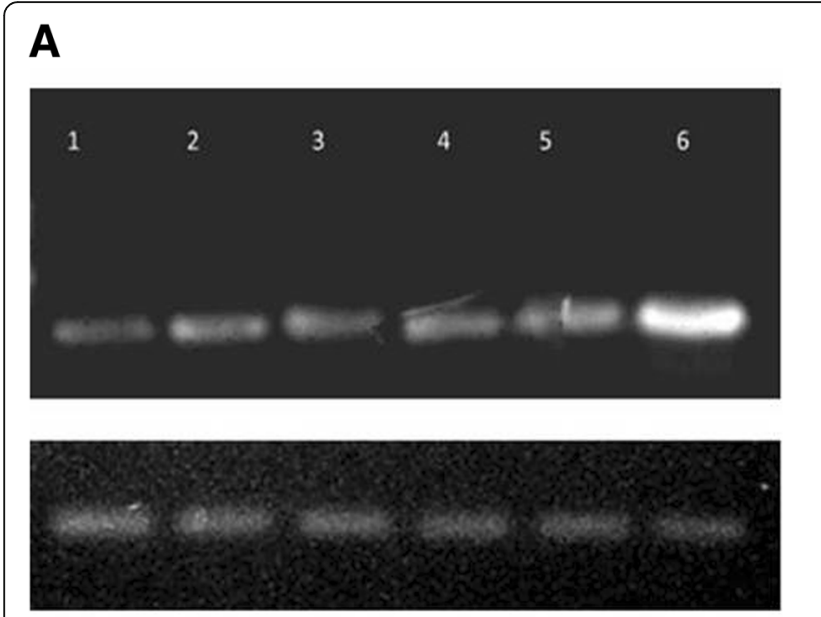

B

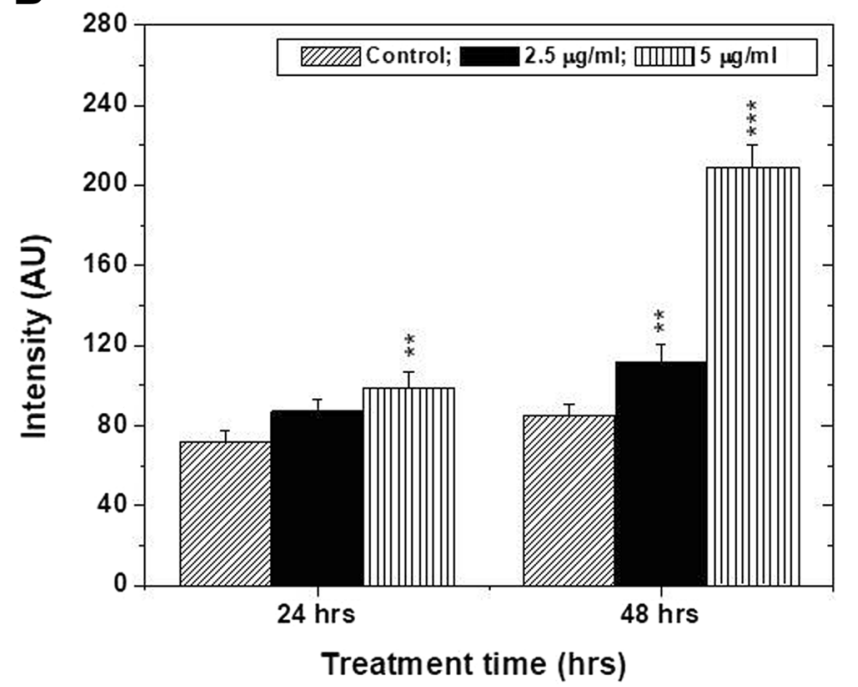

Fig. 12 A: Expression of $N$ cadherin post treatment with AiP1: Lane 1 is Control ( $24 \mathrm{~h}) ; 2$ is $2.5 \mu \mathrm{g} / \mathrm{ml} \mathrm{AiP1}(24 \mathrm{~h}) ; 3$ is $5 \mu \mathrm{g} / \mathrm{ml}$ AiP1 ( $24 \mathrm{~h}$ ); 4 is Control (48 h); 5 is $2.5 \mu \mathrm{g} / \mathrm{ml} \mathrm{AiP1} \mathrm{(48} \mathrm{h);} 6$ is $5 \mu \mathrm{g} / \mathrm{ml} \mathrm{AiP1} \mathrm{(48} \mathrm{h).} \mathrm{B:} \mathrm{Densitometric} \mathrm{analysis} \mathrm{of} \mathrm{N}$-cadherin expression post treatment with AiP1. ${ }^{*} p<0.05 ;{ }^{* *} p<0.01 ;{ }^{* * *} p<0.001$

plays an instrumental role in hemostasis by forming a complex with collagen in the sub-endothelial wall and concurrently binding to specific receptors on the platelet surface, the glycoprotein (GP) Ib/V/IX complex, and the activated GPIIb/IIIa complex thus forming a bridge between collagen(s) and platelets (Kehrel et al., 1998). Majority of vWFA-containing proteins are all intracellular proteins involved in DNA repair, transcription, ribosomal, and membrane transport. Proteins that incorporate vWFA-like domains contribute in numerous biological processes like blood coagulation, platelet adhesion and aggregation, cell adhesion, migration, homing, pattern formation, and signal transduction (Bork, 1991; Colombatti et al., 1993; Perkins et al., 1994). Combination of experimental results and peptide mass fingerprinting analysis of AiP1 helped us hypothesize the function of AiP1 in following ways:

1. The wound healing activity of AiP1 could be attributed to the presence of vWFA-like domain in it, which is known to aid in cell migration and adhesion (Hassan et al., 2012). AiP1-treated cells also showed an increase in $\mathrm{N}$-cadherin levels (Fig. 12), indicating the acceleration of cell migration and eventually faster wound closure compared to untreated cells.

2. There may also be an unidentified metalloproteinase domain in AiP1 which contributes to its thrombolytic activity ("Inhibition of fibrinogenolytic activity of AiP1" section). Since no other protein contaminations were detected by HPLC, the same protein AiP1 may have another domain responsible for its metalloproteinase activity.

The presence of a metalloproteinase domain and the vWFA-like domain in the central $\beta$ sheet of AiP1 could be responsible for its effects on hemostasis. vWF promotes fibrin formation in response to arterial injury in a site-directed manner as a result of its function as a chaperone for factor VIII and ligand for sub-endothelial collagen. It forms covalent crosslinks with fibrin and modifies its structure (increasing its diameter) which enhances fibrinolysis and fibrin polymerization (Marchi \& Rojas, 2015; Spiel, Gilbert, \& Jilma, 2008). The von Willebrand factor may have a dual role in the hemostatic process: under high shear stress, the vWF enhances platelet aggregation and thrombus formation; at low concentrations, it causes thrombolysis and wound healing (Miszta et al., 2014). Adhesion of platelets and collagen is enhanced via binding of vWF at high shear rates (Laduca, Bell, \& Bettigole, 1987). The initial binding occurs between vWF and GPIb, which is further supported by interaction of platelet receptor GPIIa/IIIb with fibrinogen (Miszta et al., 2014). This could possibly explain the effects of AiP1 on platelet aggregation, fibrinogenolysis, and fibrinolysis (Delaney et al., 2014; Skipwith, Cao, \& Zheng, 2010; Wu, de Groot, \& Sixma, 1997).

The increase in platelet aggregation upon treatment with AiP1 at doses up to $2.5 \mu \mathrm{g} / \mathrm{ml}$ might be due to the attachment of the vWFA-like domain present in it, which binds platelets to collagen and promotes aggregation. Time- and dose-dependent fibrinogenolysis and fibrinolysis of AiP1 could be due to the dual role of the 
vWFA-like domain present in it. However, the exact mechanism needs to be deciphered. The fibrinogenolytic, fibrinolytic, and wound healing activity of AiP1 could further be explored using in vivo models. The absence of hemolytic and phospholipase activities in AiP1 render it safe for further drug development.

These findings suggest that vWFA-like domain is the most important region of the AiP1 protein for its thrombolytic and wound healing activities. It remains to be seen whether this domain is also responsible for other biological activities.

\section{Conclusion}

We report a novel protein AiP1 from the sea star Astropecten indicus and its thrombolytic and wound healing potential. The protein being fibrinogenolytic and fibrinolytic in nature could provide a drug lead as a potent anticoagulant without significant hemolytic and phospholipase activities. AiP1 was also found to increase cell proliferation and enhanced wound closure rates in vitro. The wound healing and platelet aggregating activities may be attributed to the vWFA domain. However, the domain responsible for metalloproteinase activity is not yet identified. Results of this study advocates further aggressive research on exploration of therapeutic from echinoderms.

\section{Additional file}

Additional file 1: Table S1. Peptide Fragments of AiP1 and their top NCBI BLAST hits scanned against NCBI nr database. (PDF 198 kb)

\section{Abbreviations}

ADP: Adenosine di-phosphate; CBB R-250: Coomassie Brilliant Blue R-250 Dye; DEAE Sephadex: Diethyl amino ethyl Sephadex; DMEM: Dulbecco's modified Eagle's medium; DMSO: Dimethylsulfoxide; EDTA: Ethylene diamine tetra acetic acid; EMT: Epithelial to mesenchymal transition; FBS: Fetal bovine serum; HaCaT: Human keratinocytes; HEK293: Human Embryonic Kidney cell line; KPB: Potassium phosphate buffer; MTT: 3-(4,5-Dimethylthiazol-2-yl)-2,5diphenyltetrazolium bromide) tetrazolium; PBS: Phosphate buffer saline; PMSF: Phenylmethylsulfonylfluoride; SCF: Sea star coelomic fluid; VWF: von Willebrand factor

\section{Acknowledgements}

The authors are grateful to Mr. Gurudas and Mr. Santosh (lifeguards of South Goa beaches) for their unconditional help in the collection and release of the sea stars. The authors thank Dr. Indrani Talukdar for providing HEK293 cell stocks and Ms. Chitra Nair for their general support for performing the molecular biology experiments.

\section{Authors' contributions}

$M B, D C, A S$, and SM participated in the design of this research and performed the data analysis. MB conducted all the experiments except cDNA synthesis and cadherin expression studies. JS performed CDNA synthesis and expression of $\mathrm{N}$ and $\mathrm{E}$ cadherin studies. MB, DC, SM, and AS wrote the manuscript. All authors read and approved the final manuscript.

\section{Funding}

The authors are grateful to Birla Institute of Technology and Science, Pilani, for the partial support of this study in the form of a Seed-Grant to DC. The study also partially benefitted from a Department of Biotechnology sponsored project (BT/PR5713/BRB/10/1112/2012). MB was supported by the DST-INSPIRE fellowship (IF130142).

\section{Availability of data and materials}

The dataset(s) supporting the conclusions of this article are included within the article (and in the supplementary data). The authors can be contacted for any additional supporting data required by the journal.

\section{Ethics approval and consent to participate}

The authors declare that no animal was sacrificed for this study. Blood for platelet aggregation studies was withdrawn under medical supervision with prior consent from the volunteers.

Human Ethical Approval for the project titled "Study of Hemotoxic and Cytotoxic Agents from Sea star (Starfish) Coelomic Fluid" via approval number IHEC-43/17-1 was obtained from the Institute Human Ethical Committee (IHEC) BITS, Pilani (Birla Institute of Technology and Science-Pilani).

\section{Consent for publication}

This manuscript does not contain any individual person's data.

\section{Competing interests}

The authors declare that they have no competing interest.

Received: 9 January 2019 Accepted: 14 June 2019

Published online: 15 July 2019

\section{References}

Baveja, M., Sarkar, A., \& Chakrabarty, D. (2018). Hemotoxic and wound healing potential of coelomic fluid of sea-star Astropecten indicus. The Journal of Basic and Applied Zoology, 79, 27.

Berridge, M. V., Herst, P. M., \& Tan, A. S. (2005). Tetrazolium dyes as tools in cell biology: New insights into their cellular reduction. In Biotechnology Annual Review, (pp. 127-152). Elsevier.

Bienert, S., Waterhouse, A., de Beer, T. A. P., Tauriello, G., Studer, G., Bordoli, L., \& Schwede, T. (2017). The SWISS-MODEL Repository-new features and functionality. Nucleic Acids Research, 45, D313-D319.

Bordbar, S., Anwar, F., \& Saari, N. (2011). High-value components and bioactives from sea cucumbers for functional foods - a review. Marine Drugs, 9, 1761-1805.

Bork, P. (1991). Shuffled domains in extracellular proteins. FEBS Letters., 286, 47-54.

Bradford, M. M. (1976). A rapid and sensitive method for the quantitation of microgram quantities of protein utilizing the principle of protein-dye binding. Analytical Biochemistry, 72, 248-254.

Butera, D., Passam, F., Ju, L., Cook, K. M., Woon, H., Aponte-Santamaría, C., et al. (2018). Autoregulation of von Willebrand factor function by a disulfide bond switch. Science Advances, 4, eaaq1477.

Chanda, C., Sarkar, A., \& Chakrabarty, D. (2016). Thrombolytic protein from cobra venom with anti-adhesive properties. Archives of Biochemistry and Biophysics, 590, 20-26.

Chanda, C., Sarkar, A., Sistla, S., \& Chakrabarty, D. (2013). Anti-platelet activity of a three-finger toxin (3FTx) from Indian monocled cobra (Naja kaouthia) venom. Biochemical and Biophysical Research Communications, 441, 550-554.

Choi, Y.-H., Yang, D. J., Kulkarni, A., Moh, S. H., \& Kim, K. W. (2015). Mycosporinelike amino acids promote wound healing through Focal Adhesion Kinase (FAK) and Mitogen-Activated Protein Kinases (MAP Kinases) signaling pathway in keratinocytes. Marine Drugs, 13, 7055-7066.

Colombatti, A., Bonaldo, P., \& Doliana, R. (1993). Type A modules: interacting domains found in several non-fibrillar collagens and in other extracellular matrix proteins. Matrix, 13, 297-306.

da Silva Laires, R. d. A. (2012). Characterization of the coelomic fluid of the starfish Marthasterias glacialis in a wound-healing phase.

Dai, Y., Prithiviraj, N., Gan, J., Zhang, X. A., \& Yan, J. (2016). Tissue extract fractions from starfish undergoing regeneration promote wound healing and lower jaw blastema regeneration of zebrafish. Scientific Reports, 6 .

Datta, D., Nath Talapatra, S., \& Swarnakar, S. (2015). Bioactive compounds from marine invertebrates for potential medicines - an overview. International Letters of Natural Sciences, 34, 42-61.

Delaney, M. K., Liu, J., Kim, K., Shen, B., Stojanovic-Terpo, A., Zheng, Y., ... Du, X. (2014). Agonist-induced platelet procoagulant activity requires shear and a Rac1-dependent signaling mechanism. Blood, 124, 1957-1967.

Dhole, K., Singh, G., Pai, P. P., \& Mondal, S. (2014). Sequence-based prediction of protein-protein interaction sites with L1-logreg classifier. Journal of Theoretical Biology, 348, 47-54.

Engelmann, B., \& Massberg, S. (2013). Thrombosis as an intravascular effector of innate immunity. Nature Reviews Immunology, 13, 34-45. 
Guo, S., \& DiPietro, L. A. (2010). Factors affecting wound healing. Journal of Dental Research, 89, 219-229.

Hall, M. R., Kocot, K. M., Baughman, K. W., Fernandez-Valverde, S. L., Gauthier, M. E. A., Hatleberg, W. L., et al. (2017). The crown-of-thorns starfish genome as a guide for biocontrol of this coral reef pest. Nature.

Hamed, I., Özogul, F., Özogul, Y., \& Regenstein, J. M. (2015). Marine bioactive compounds and their health benefits: a review. Comprehensive Reviews in Food Science and Food Safety, 14, 446-465.

Han, G., \& Ceilley, R. (2017). Chronic wound healing: a review of current management and treatments. Advances in Therapy, 34, 599-610.

Hassan, M. I., Saxena, A., \& Ahmad, F. (2012). Structure and function of von Willebrand factor. Blood Coagul Fibrinolysis, 23, 11.

Inada, M., Izawa, G., Kobayashi, W., \& Ozawa, M. (2016). 293 cells express both epithelial as well as mesenchymal cell adhesion molecules. International Journal of Molecular Medicine, 37, 1521-1527.

Johnson, M., Zaretskaya, I., Raytselis, Y., Merezhuk, Y., McGinnis, S., \& Madden, T. L. (2008). NCBI BLAST: a better web interface. Nucleic Acids Research, 36, W5-W9.

Kehrel, B., Wierwille, S., Clemetson, K. J., Anders, O., Steiner, M., Knight, C. G., ... Barnes, M. J. (1998). Glycoprotein VI is a major collagen receptor for platelet activation: it recognizes the platelet-activating quaternary structure of collagen, whereas CD36, glycoprotein Ilb/llla, and von Willebrand factor do not. Blood, 91, 491-499.

Key, N. S., Makris, M., \& Lillicrap, D. (2016). Practical hemostasis and thrombosis. Wiley.

Kijjoa, A., \& Sawangwong, P. (2004). Drugs and cosmetics from the sea. Marine Drugs, 2, 73-82

Laduca, F. M., Bell, W. R., \& Bettigole, R. E. (1987). Platelet-collagen adhesion enhances platelet aggregation induced by binding of WWF to platelets. American Journal of Physiology-Heart and Circulatory Physiology, 253, H1208-H1214.

Lau, W. C. (2003). Atorvastatin reduces the ability of clopidogrel to inhibit platelet aggregation: a new drug-drug interaction. Circulation, 107, 32-37.

Leber, T. M., \& Balkwill, F. R. (1997). Zymography: a single-step staining method for quantitation of proteolytic activity on substrate gels. Analytical Biochemistry, 249, 24-28.

Liang, C.-C., Park, A. Y., \& Guan, J.-L. (2007). In vitro scratch assay: a convenient and inexpensive method for analysis of cell migration in vitro. Nature Protocols, 2, 329-333.

Maitre, J.-L., \& Heisenberg, C.P. (2013). Three functions of cadherins in cell adhesion. Current Biology, 23, R626-R633.

Marchi, R., \& Rojas, H. (2015). Effect of von Willebrand factor on clot structure and lysis. Blood Coagulation \& Fibrinolysis International Journal Haemost. Thromb., 26, 533-536.

Masure, S., Proost, P., Van Damme, J., \& Opdenakker, G. (1991). Purification and identification of $91-\mathrm{kDa}$ neutrophil gelatinase. European Journal of Biochemistry, 198, 391-398.

Matsushita, T., \& Sadler, J. E. (1995). Identification of amino acid residues essential for von Willebrand factor binding to platelet glycoprotein Ib. Charged-toalanine scanning mutagenesis of the A1 domain of human von Willebrand factor. Journal of Biological Chemistry, 270, 13406-13414.

Miszta, A., Pelkmans, L., Lindhout, T., Krishnamoorthy, G., Groot, P., Hemker, C., ... Laat, B. (2014). Thrombin-dependent Incorporation of von Willebrand Factor into a Fibrin Network. Journal of Biological Chemistry, 289, 35979-35986.

Montaser, R., \& Luesch, H. (2011). Marine natural products: a new wave of drugs? Future Medicinal Chemistry, 3, 1475

Pathan, J., Mondal, S., Sarkar, A., \& Chakrabarty, D. (2017). Daboialectin, a C-type lectin from Russell's viper venom induces cytoskeletal damage and apoptosis in human lung cancer cells in vitro. Toxicon, 127, 11-21.

Patravale, V., Dandekar, P., \& Jain, R. (2012). 4 - Nanotoxicology: evaluating toxicity potential of drug-nanoparticles. In Nanoparticulate Drug Delivery, (pp. 123155). Woodhead Publishing.

Perkins, S. J., Smith, K. F., Williams, S. C., Haris, P. I., Chapman, D., \& Sim, R. B. (1994). The secondary structure of the von Willebrand factor type A domain in factor B of human complement by Fourier transform infrared spectroscopy. Its occurrence in collagen types VI, VII, XII and XIV, the integrins and other proteins by averaged structure predictions. Journal of Molecular Biology, 238, 104-119.

Peyvandi, F., Garagiola, I., \& Luciano, B. (2011). Role of von Willebrand factor in the haemostasis. Blood Transfusion, 9, s3-s8.

Priya, R., \& Yap, A. S. (2015). Making a choice: how cadherin switching controls cell migration. Developmental cell, 34, 383-384.

Ruggeri, Z. M. (1997). von Willebrand factor. The Journal of clinical investigation, $99,559-564$.
Skipwith, C. G., Cao, W., \& Zheng, X. L. (2010). Factor VIII and platelets synergistically accelerate cleavage of von Willebrand Factor by ADAMTS13 under fluid shear stress. Journal of Biological Chemistry, 285, 28596-28603.

Spiel, A. O., Gillbert, J. C., \& Jilma, B. (2008). Von Willebrand factor in cardiovascular disease: focus on acute coronary syndromes. Circulation, 117, 1449-1459.

Strober, W. (2015). Trypan Blue exclusion test of cell viability: Trypan Blue exclusion test of cell viability. In J. E. Coligan, B. E. Bierer, D. H. Margulies, E. M. Shevach, \& W. Strober (Eds.), Current protocols in immunology, (pp. A3.B.1A3.B.3). Hoboken: Wiley.

Wu, Y. P., de Groot, P. G., \& Sixma, J. J. (1997). Shear-stress-induced detachment of blood platelets from various surfaces. Arteriosclerosis, Thrombosis, and Vascular Biology, 17, 3202-3207.

Zuppinger, C., Eppenberger-Eberhardt, M., \& Eppenberger, H. M. (2000). N-Cadherin: structure, function and importance in the formation of new intercalated disclike cell contacts in cardiomyocytes. Heart Failure Reviews, 5, 251-257.

\section{Publisher's Note}

Springer Nature remains neutral with regard to jurisdictional claims in published maps and institutional affiliations.

\section{Submit your manuscript to a SpringerOpen ${ }^{\circ}$ journal and benefit from:}

- Convenient online submission

- Rigorous peer review

- Open access: articles freely available online

- High visibility within the field

- Retaining the copyright to your article

Submit your next manuscript at $\boldsymbol{\nabla}$ springeropen.com 